\title{
Study on Quality Improvement of MTI Talent Training Based on the OBE Philosophy \\ Xiaohong Shen ${ }^{1}$ and Hongbo Song ${ }^{2}$ \\ ${ }^{1}$ School of Foreign Languages, Wuhan University of Science and Technology \\ ${ }^{2}$ School of Foreign Languages, Wuhan University of Science and Technology \\ 1183623543@qq.com, ${ }^{2} 540312904 q q . c o m$
}

Keywords: OBE philosophy; MTI talent training quality; Talent training model; Curriculum setting

\begin{abstract}
The low quality of MTI talent training has become a consensus in the industry, and improving the MTI talent training quality is consistent with the OBE philosophy that is oriented at students' learning outcomes. In this paper, based on the OBE philosophy, strategies are proposed to improve the quality of MTI talent training from two aspects: the talent training mode and curriculum setting.
\end{abstract}

\section{Introduction}

In order to meet the needs of China's reform and opening up and the development of socialist modernization, promote exchanges between China and foreign countries, and train high-level, applied translators, the State Council's Academic Degrees Committee approved the establishment of Master of Translation and Interpreting (MTI) at the $23^{\text {rd }}$ meeting on January 23, 2007. Compared with the traditional academic master's degree in translation, the Master of Translation and Interpreting puts special emphasis on practicality. The enrollment targets of MTI are generally bachelor's degree holders with a good bilingual foundation, and those who have translation and interpreting experiences are preferred. Besides, students from different majors and academic backgrounds are encouraged to apply for the MTI degree. In terms of talent training, the teaching contents highlight the training of oral and written translation skills and focus on cultivating students' practical translation and interpreting capacity. Thus, it can be seen that being practical is the most prominent feature of MTI, which determines all aspects of the training of MTI talents.

After a decade of development, great achievements have been made in the professional construction of MTI, but the problems are becoming increasingly prominent: Unclear education philosophy; Poor professional construction; Loose teaching management; The training program is not systematic; The faculty is not strong; The Practice base is not up to standard; The school resources are insufficient; The teaching quality is not high (PING Hong, 2016:49-53). Scholar ZHONG Weihe also clearly stated that: "at present, the above problems more or less exist in the MTI education. Meanwhile, we are also faced with the eighth problem, i.e., the quality of talent training is not high. If these problems cannot be resolved in a short time, they will greatly affect the development of MTI and the construction of translation and interpreting subjects." (ZHONG Weihe, 2017:7-9). All the above-mentioned problems have finally led to the low quality of MTI talent training. Thus, to improve the quality of MTI talent training is not only the start point but also the ultimate goal of resolving the various problems in the development of MTI.

Talent training quality directly reflects students' learning results. The thought of taking the improvement of talent training quality as the start point and the ultimate goal of resolving the various problems in running the MTI program is consistent with the Outcome Based Education (OBE in short) philosophy.

\section{Outcome Based Education Philosophy}

The OBE mode first appeared in the basic education reforms in the United States and Australia. Since it was founded by Spady W.D. in 1981, it has been sought after by the educational circles all 
around the world. In 2000, the U.S. Accreditation Board for Engineering and Technology (ABET) took the lead to start the "outcome based" accreditation criteria "Engineering Criteria 2000" (EC2000), exerting an essential influence on engineering education in the United States. In 2004-2005, the United States, Britain, Australia, Canada, New Zealand, South Africa, Japan and Ireland established the "Washington Accord: Graduate Attributes" ("Washington Accord" in short), indicating that OBE became the mainstream philosophy of educational reform in the U.S., U.K., Canada and other countries. China's OBE educational reform started in Taiwan. In 2004, Taiwan's "educational departments" launched "Awarding Outstanding College Teaching Program" and developed nine basic core teaching indicators, including the requirements for promoting the OBE curriculum reform (MA Jinjing, 2012). GU Peihua, HU Wenlong et al. (2013) introduced the practice and exploration of OBE engineering education model at Shantou University in recent years, which has provided reference for the implementation of OBE engineering education model at colleges and universities.

\section{Guide the MTI Talent Training Model Reform with OBE Philosophy}

The OBE is oriented at students' learning outcomes. Teachers should focus on the problem "what can indeed make students who have learned experience to succeed?" (LI Kunchong, 2011:3) to organize everything in the educational system so as to promote the focus of educational reform from emphasizing resource investment to emphasizing learning outcomes. Besides, the school and teachers should shoulder the responsibility for students' learning outcomes. In OBE, all students are expected and allowed to succeed in study, and in order to ensure this, all efforts should be made to create and expand chances of success for students as much as possible.

At present, the MTI talent training model adopted at colleges and universities does not differ greatly from that of academic master's degree of translation. Take the 3-year MTI program as an example, most colleges and universities adopt the " $1.5+0.5+1$ " model, i.e., the students should first take academic courses at school for one year and a half, and then take a half-a-year internship outside campus. For the last year, they will prepare for the graduation thesis. In this model, the students spend $2 / 3$ of their time on curriculum learning, and in most courses, there is little practice in translation skills. Besides, the in-class translation practice differs a lot from language service enterprises' practical translation or interpreting projects in terms of quality and process control, so students can receive very limited translation or interpreting guidance and improvement. One-third of the time is spent on writing the graduation thesis, and only one-sixth time is left for internships. This model not only does not create and extend the chances of success for students, but also limits their chances of success, so it is not conducive to training students' translation and interpreting capacity nor the improvement of MTI talent training quality. Therefore, the MTI talent training model must be reformed.

According to the OBE philosophy, the new MTI talent training model must be able to create and extend chances of success for students. It is found from the real MTI training at colleges and universities that the chances of success that student lack are practical resources such as translation projects and specific guidance from MTI teachers with practical translation experiences.

The practical resources and practical teachers that colleges and universities lack can both be obtained from language service enterprises. Therefore, the direction of MTI talent training model reform is school-enterprise cooperation.

In order to mobilize enterprises to actively participate in school-enterprise cooperation and support colleges and universities to train MTI talents, it is necessary to find the interest points with which enterprises are willing to participate in cooperation. Language service enterprises can and hope to obtain the MTI talents that are needed by them. The "order class" is an effective model for deep cooperation between schools and enterprises with talents as the point for mutual point. However, if colleges and universities just simply regard the order enterprises as an exit for students' internship and employment, the order enterprises can only "reap the benefits", waiting for students of the order class to graduate and get employed. In this way, this is just a "pseudo-order" as the "products" (students) of this order are "unqualified products" for the employing enterprise, and the 
enterprise eventually request to return the students. Without the benefit of talents, enterprises will inevitable lose interest in continuing to cooperate with schools, and schools can no longer obtain support from enterprises in talent training.

To ensure the implementation of the "order class" model at the MTI training, the following four aspects should be noted:

First, Colleges and universities should choose language service enterprises with sufficient strength, preferably a language service enterprise with brand offices because in such enterprise, there are more project managers, full-time and part-time translators and quality managers, so it can provide more chances and guidance in translation practice for MTI students.

Second, Colleges and universities should clarify the enterprise's obligations in the "order class" cooperation agreement, which must include the formulation of MTI talent training scheme with the participation of enterprises, enterprises shall undertake the teaching of $\mathrm{N}$ courses and give the school at least chance to participate in translation projects, and enterprises should deliver industrial training to full-time teachers at the school for $\mathrm{N}$ hours every semester, etc.

Third, for more in-depth and effective cooperation between schools and enterprises, it is suggested to adopt the "double-tutor system" for the "order class". According to the features of the translation project team, 3-4 students can form a project team and share one tutor. The on-campus tutor and the enterprise tutor shall jointly train the 3-4 students: the enterprise tutor is responsible for guiding students in short-time practical translation projects, and the on-campus tutor is responsible for the student's on-campus curriculum, graduation thesis and student management, etc. Fourth, Taking into account the periodicity and timeliness of corporate translation projects, it is recommended that MTI degrees be borrowed from the management mode of "replacement of learning and practice" at vocational colleges and that flexible teaching management be implemented.

\section{Guide the MTI Curriculum Setting with the OBE Philosophy}

The curriculum is the concrete embodiment and guarantee of the MTI training goal, and it is the fundamental way to improve the quality of MTI talents training. The current MTI program is not reasonable, which is mainly reflected in the following two aspects:

First, The curriculum is incomplete. In MTI's education practice, it is not possible to simply copy the curriculum of the "Guideline Training Program" and it should be advancing with the times. A market-oriented curriculum system should be constructed based on the analysis results of professional talent demand research to ensure that the quality of MTI talent training is in line with The needs of language service enterprises.

Second, The curriculum does not emphasize the development of translation skills. The proportion of translation practice courses in the MTI curriculum system is low. As mentioned above, MTI focuses on the students' translation ability, and the practicality is the most prominent feature of the master degree in translation. Therefore, in the MTI curriculum system, additional translation practice courses should be added and the proportion of practical class hours in the total course time of the curriculum should be increased. .

The implementation of the OBE philosophy requires that educators first define learning outcomes, that is, build a blueprint for the results. The results blueprint describes the graduates' expected ability structure, which needs to be achieved through the curriculum system. Therefore, the development and design curriculum and component curriculum system play an important role in students' achievement of the blueprint. The curriculum system must comprehensively cover the competency indicators, establish a clear mapping relationship between the two, and require students to complete all the expected learning outcomes after completing the course system.

In view of this, a full and comprehensive talent demand survey must be conducted before the MTI curriculum is set up. Such talent demand research is conducted at least once a year to ensure that the information obtained through research advances with the times, and strives to grasp the translation industry and language service enterprises through research. The specific requirements for MTI talents are based on this and build a blueprint for MTI results. Under the guidance of the 
results blueprint, the author recommends that the MTI curriculum system be modularly constructed and consist of five major modules. they are, respectively:

Translation ability course module: The main courses include economic and trade translation, science and technology translation, media translation, legal translation, and MTI courses at colleges and universities.

Interpreting ability course module: The main courses include business interpreting, conference interpreting, court interpreting and MTI courses at colleges and universities.

Translation technology capability module: The main courses include computer-assisted translation (CAT), localization technologies, terminology libraries, and so on.

Translators' professional literacy module: The main courses include translator career, interpreter public relations etiquette, translation industry's development, translation project management and so on.

Translation project practice module: 1 translation project per semester.

Among them, the (4) module translators' professional literacy courses are delivered by part-time teachers of cooperative enterprises. The (5) module translation project practice includes 1 translation project per semester, and the project comes from the "ordering order" cooperative enterprise. According to the specific situation of the enterprise at present, the enterprise tutor is responsible for the project schedule and quality control, and the on-campus tutor cooperates with the tutor of the enterprise to give specific guidance to students.

\section{Conclusion}

To improve the quality of MTI talent training, it is urgent to reform the current talent training model and improve the curriculum setting. The OBE philosophy can provide new theoretical guidance for MTI training units in talent training model and curriculum setting and promote the improvement of MTI talent training quality.

\section{References}

[1] Hong Ping, Reflections on the Development of MTI Education in China [J]. Chinese Translators Journal, 2016(5):49-53.

[2] Weihe Zhong, Ten Years Sail, Going Forward: The MTI Education Decade Review and Prospect [J]. Chinese Translators Journal, 2017(3):7-9.

[3] Spady, W. D. Outcome-Based Education: Critical Issues And Answers [M]. Arlington, VA: The American Association of School Administrators, 1994.

[4] Jinjing Ma, A Research on the Development of Doctoral Programs for Result-oriented Education: Taking Education Leadership and Management as an Example [D]. Southwest University Doctoral Dissertation, 2012.

[5] Peihua Gu, HU Wenlong, LIN Peng, BAO Nengsheng, LU Xiaohua, XIONG Guangjing, CHEN Yan, Engineering Education Model Based on “Outcome Based Education” (OBE) [J]. Higher Engineering Education Research, 2014(1):27-37.

[6] Kunchong Li, Evaluation of College Curriculum Development and Learning Effect [M]. Taipei: Higher Education Culture Co., Ltd., 2011:3. 